Jurnal Ekonomi, Bisnis, dan Akuntansi (JEBA) Volume 21 Nomor 02 Tahun 2019

\title{
MENILAI PENGARUH CITRA MEREK, KERAGAMAN MENU, SUASANA TOKO DAN KUALITAS PRODUK TERHADAP KEPUASAN KONSUMEN DAN NIAT BELI ULANG (STUDI PADA KONSUMEN SOCIETY COFFEE HOUSE PURWOKERTO)
}

\author{
Esa Yanri Mekar Lorena 1), Sri Martini 2)
}

1) Alumni Fakultas Ekonomi dan Bisnis Universitas Jenderal Soedirman

2) Dosen Fakultas Ekonomi dn Bisnis Universitas Jenderal Soedirman

*Email corresponding author : esayml@gmail.com

\begin{abstract}
This study aimed to analyze the effects arising from the Brand Image, Menu Variety, Store Atmosphere and Product Quality on Consumer Satisfaction and its influence on Purchase Intention from consumer of Society Coffee House Purwokerto. The variables used in this study is Brand Image, Menu Variety, Store Atmosphere and Product Quality as independent variables, then the Consumer Satisfaction as an intervening variable and Purchase Intention as the dependent variable. The samples in this study is consumers of Society Coffee House Purwokerto with some 165 people by using Purposive Sampling technique. In this study developed a theoretical model to propose five hypotheses to be tested using analysis tools Structural Equation Modeling (SEM) which is operated through a program AMOS 21.0. The result of SEM analysis showed that the variable of Brand Image, Menu Variety, Store Atmosphere and Product Quality had positive influences on Consumer Satisfaction and Consumer Consumer Satisfaction and its influence on Purchase Intention. And than the results of hypothesis testing showed that the Purchase Intention can be improved by increasing Brand Image, Menu Variety, Store Atmosphere and Product Quality affect the Customer Satisfaction as a determinant of success increase Purchase Intention.
\end{abstract}

Keywords: Purchase Intention, Consumer Satisfaction, Brand Image, Menu Variety, Store Armosphere and Product Quality

\begin{abstract}
ABSTRAK
Penelitian ini bertujuan untuk menganalisis pengaruh yang timbul dari Citra Merek, Variasi Menu, Suasana Toko dan Kualitas Produk terhadap Kepuasan Konsumen dan pengaruhnya terhadap Niat Pembelian dari konsumen Coffee House Society Purwokerto. Variabel-variabel yang digunakan dalam penelitian ini adalah Citra Merek, Keragaman Menu, Suasana Toko dan Kualitas Produk sebagai variabel independen, kemudian Kepuasan Konsumen sebagai variabel intervening dan Intensi Pembelian sebagai variabel dependen. Sampel dalam penelitian ini adalah konsumen Rumah Kopi Masyarakat Purwokerto dengan jumlah 165 orang dengan menggunakan teknik Purposive Sampling. Dalam penelitian ini dikembangkan model teoritis untuk mengajukan lima hipotesis yang akan diuji menggunakan alat analisis Structural Equation Modeling (SEM) yang dioperasikan melalui program AMOS 21.0. Hasil analisis SEM menunjukkan bahwa variabel Citra Merek, Keragaman Menu, Suasana Toko dan Kualitas Produk berpengaruh positif terhadap Kepuasan Konsumen dan Kepuasan Konsumen Konsumen serta pengaruhnya terhadap Niat Beli. Dan dari hasil pengujian hipotesis menunjukkan bahwa Intensi Pembelian dapat ditingkatkan dengan meningkatkan Citra Merek, Keragaman Menu, Suasana Toko dan Kualitas Produk mempengaruhi Kepuasan Pelanggan sebagai penentu keberhasilan peningkatan Intensi Pembelian.
\end{abstract}

Kata Kunci : Niat Beli, Kepuasan Konsumen, Citra Merek, Keragaman Menu, Suasana Toko, Kualitas Produk 


\section{PENDAHULUAN}

Era globalisasi ini mengubah banyak hal, termasuk gaya hidup masyarakat. Khususnya bagi pemuda dan orang dewasa yanng mulai memiliki gaya hidup berkumpul di sebuah cafe atau coffee shop untuk sekedar menghabiskan waktu atau mengerjakan tugas dan pekerjaan. Setiap cafe dan coffee shop pastinya mengharapkan adanya pembelian ulang secara terus menerus dari konsumennya. Penelitian yang dilakukan Kisang Ryu dkk (2016) menyatakan bahwa kepuasan konsumen berpengaruh pada keinginan berperilaku positif konsumen yang di dalamnya termasuk niat membeli ulang. Sedangkan kepuasan konsumen dapat dibentuk oleh beberapa faktor, salah satunya citra merek citra merek cafe atau coffee shop. Menurut Chi and $\mathrm{Qu}$ (2008), corporate image mempengaruhi niat konsumen berkunjung kembali. Park, Jaworski dan Maclnnis (1986) mengemukakan bahwa citra merek merupakan fenomena perseptual yang dipengaruhi oleh kegiatan di dalam perusahaan yang dapat membuat konsumen mengaitkan pikiran mereka dengan produk bermerek.

Pertumbuhan bisnis restoran dan cafe di Kabupaten Banyumas juga mengalami kenaikan yang sangat pesat beberapa tahun terakhir. Dalam data Badan Pusat Statistik (Jawa Tengah) tahun 2012-2015 tercatat pertumbuhan usaha restoran dan cafe di Kabupaten Banyumas sekitar 335\%, dari yang semula jumlah restoran dan cafe pada tahun 2012 sebanyak 46 menjadi 200 di tahun 2015. Purwokerto sebagai pusat pertumbuhan ekonomi Kabupaten Banyumas tentu menyumbang banyak angka dalam pertumbuhan usaha restoran dan cafe tersebut. Dapat dilihat daftar coffee shop dan cafe di Purwokerto yang menyajikan minuman kopi dengan rating-nya yang cukup baik beserta jumlah reviewers-nya di pencarian Google.

Tabel 1. Daftar Cafe dan Coffee shop dengan rating dan reviewers lima teratas di Purwokerto

\begin{tabular}{|c|c|c|c|c|}
\hline No & Nama & Alamat & Reviewers & Rating \\
\hline \multicolumn{5}{|l|}{1.} \\
\hline & Society Coffee House & Jl. Prof. Dr. Suharso No. 9B & 159 orang & $4,3 / 5$ \\
\hline 2. & Quattro Cafe & Jl. Pungkuran No. 10 & 142 orang & $4,2 / 5$ \\
\hline & Singgah Coffee \& & & & \\
\hline 3. & Book & Jalan Riyanto No.29 & 120 orang & $4,2 / 5$ \\
\hline 4. & Praketa Kopi & Jl. H.R Boenyamin No.129 & 118 orang & $4,5 / 5$ \\
\hline 5. & Djagongan Cafe & Jl. Gn Merapi Bancarkembar & 93 orang & $4,1 / 5$ \\
\hline
\end{tabular}

Sumber : Google, 2018

Berdasarkan Tabel 1 dapat dilihat bahwa Society Coffee House memiliki reviewers yang paling banyak yaitu sebanyak 159 orang dan rating yang cukup baik, yaitu 4,3/5 dibandingkan dengan coffee shop lainnya. Hal tersebut membuat Society Coffee House menjadi menarik untuk diteliti berkaitan dengan hal-hal yang mempengaruhi kepuasan konsumen dan niat beli ulang terhadap sebuah coffee shop.

\section{KERANGKA PEMIKIRAN TEORITIS DAN PERUMUSAN HIPOTESIS}

\section{Pengaruh Citra Merek terhadap Kepuasan Konsumen}

Kotler dan Armstrong (2001:298) berpendapat konsumen merasa puas apabila produk yang dibeli sesuai dengan apa yang diinginkan dan harapan dari konsumen. Menurt Kurniawati, Dewi dkk (2014), semakin baik persepsi di benak konsumen terhadap citra merek perusahaan maka kepuasan konsumen juga akan semakin tinggi. Penelitian yang telah dilakukan Dr. Fariddedin Allameh dkk (2014) bahwa food quality dan service quality berpengaruh pada mental image of restaurant dan berpengaruh positif pada kepuasan konsumen. 
Dari uraian tersebut, peneliti merumuskan hipotesis sebagai berikut :

\section{H1 : Citra merek berpengaruh positif terhadap kepuasan konsumen.}

\section{Pengaruh Keragaman Menu terhadap Kepuasan Konsumen}

Menu atribut yang di dalamnya termasuk keragaman menu merupakan hal yang dapat mempengaruhi kepuasan konsumen (Shoemaker dkk., 2005). Beberapa penelitian telah membuktikan bahwa menu berpengaruh postif terhadap kepuasan konsumen. Penelitian Ahmed Baloomy dkk (2017) menyatakan bahwa menu informasi berpengaruh terhadap niat berperilaku konsumen yang positif dengan melewati kepuasan.

Dari uraian tersebut, peneliti merumuskan hipotesis sebagai berikut :

\section{H2 : Keragaman menu berpengaruh positif terhadap kepuasan konsumen.}

\section{Pengaruh Suasana Toko terhadap Kepuasan Konsumen}

Menurut Lovelock (2011 : 12) bahwa atmosphere yang memang termasuk dalam dimensi servicescape disebut juga sebagai kondisi sekitar yang dapat berdampak pada suasana hati (mood) konsumen. Semakin suasan baik dan nyaman maka konsumen juga akan merasa semakin puas. Penelitian sebelumnya telah membuktikan bahwa ada hubungan positif antara suasana toko dan kepuasan konsumen. Faizan Ali dan Muslim Amin (2014) menyatakan bahwa lingkungan fisik berpengaruh terhadap kepuasan konsumen.

Dari uraian tersebut, peniliti merumuskan hipotesis sebagai berikut :

\section{H3 : Suasana toko berpengaruh positif terhadap kepuasan konsumen.}

\section{Pengaruh Kualitas Produk terhadap Kepuasan Konsumen}

Kualitas produk ini juga merupakan penilaian terhadap suatu produk, kualitas produk berkaitan dengan pengorbanan yang dikeluarkan pelanggan relatif terhadap apa yang akan diterimannya. Hal tersebut diperkuat dengan penelitian yang dilakukan oleh penelitian yang dilakukan oleh Ivyanno U. Canny (2014) yang juga menggunakan kualitas makanan sebagai bagian dari kualitas produk dalam objek penelitiannya yaitu restoran menyatakan bahwa terdapat hubungan yang positif antara kualitas makanan dan kepuasan konsumen.

Dari uraian tersebut, peneliti merumuskan hipotesis sebagai berikut :

\section{H4 : Kualitas produk berpengaruh positif terhadap kepuasan konsumen. \\ Pengaruh Kepuasan Konsumen terhadap Niat Beli Ulang}

Niat beli ulang merupakan salah satu wujud dari behavioral intention, hal tersebut dapat terwujud dengan pengaruh dari kepuasan konsumen. Konsumen yang puas dan mempunyai niat membeli ulang dan merekomendasikan ke orang lain cenderung akan loyal (Kandampully dan Suhartanto, 2000). Hung Che Wu dkk (2015) dalam penelitiannya menyatakan bahwa kepuasan

konsumen berpengaruh positif terhadap niat berkunjung ulang (revisit intention) atau dapat dikatakan juga niat membeli ulang dengan corporate image, kualitas layanan, rasa senang konsumen, dan gairah sebagai variabel yang memperngaruhi kepuasan konsumen. 
Dari uraian tersebut, peneliti merumuskan hipotesis sebagai berikut :

\section{H5 : Kepuasan konsumen berpengaruh positif terhadap niat beli ulang.}

Berdasarkan landasan teori dan penelitian terdahulu, maka dapat disusun kerangka pemikiran sebagai berikut

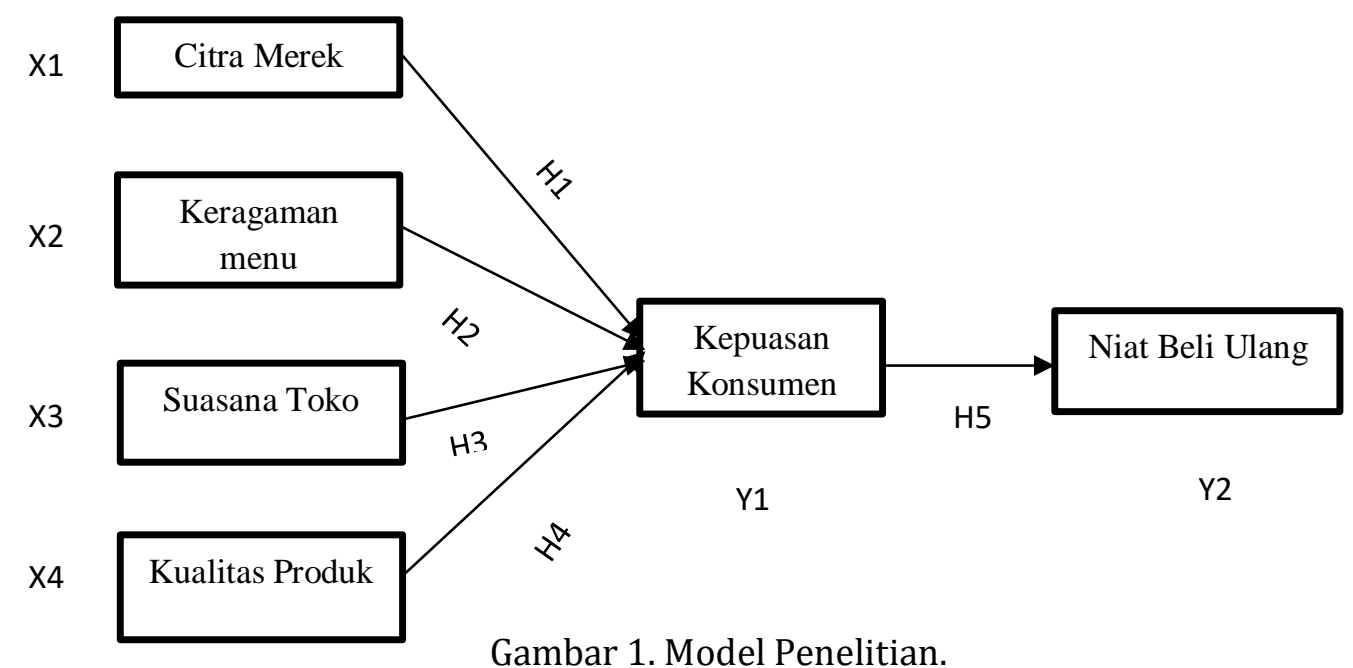

\section{Metode Penelitian}

Penelitian ini dibentuk oleh variabel independen Citra Merek, Keragaman Menu, Suasana Toko dan Kualitas Produk, sedangkan variabel dependennya adalah Kepuasan Konsumen dan Niat Beli Ulang. Masing- masing variabel dibentuk oleh beberapa indikator berdasarkan definisi operasional.

Sampel responden dalam penelitian ini adalah konsumen Society Coffee House Purwokerto yang berjumlah 165 responden. Metode analisis yang digunakan adalah Structural Equation Modelling (SEM) dengan program AMOS.

\section{HASIL PENELITIAN DAN PEMBAHASAN}

Gambaran umum responden berdasarkan data dari 165 responden, melalui daftar pertanyaan diperoleh kondisi responden mengenai jenis kelamin, usia, pekerjaan dan pendapatan yang diuraikan dalam tabel berikut :

Tabel 2. Distribusi Frekuensi Responden Berdasarkan Karakteristik Demografi

\begin{tabular}{llll}
\hline No & $\begin{array}{l}\text { Karakteristik } \\
\text { Demografi }\end{array}$ & Katagori & Frekuensi (orang) \\
\hline 1. & \multirow{2}{*}{ Jenis Kelamin } & a. Laki-laki & 79 \\
& & b. Perempuan & 86 \\
& & a. $<18$ th & 3 \\
2. & b. $18-28$ th & 148 \\
& Usia & c. $28-39$ th & 11 \\
& & d. $>40$ th & 3
\end{tabular}




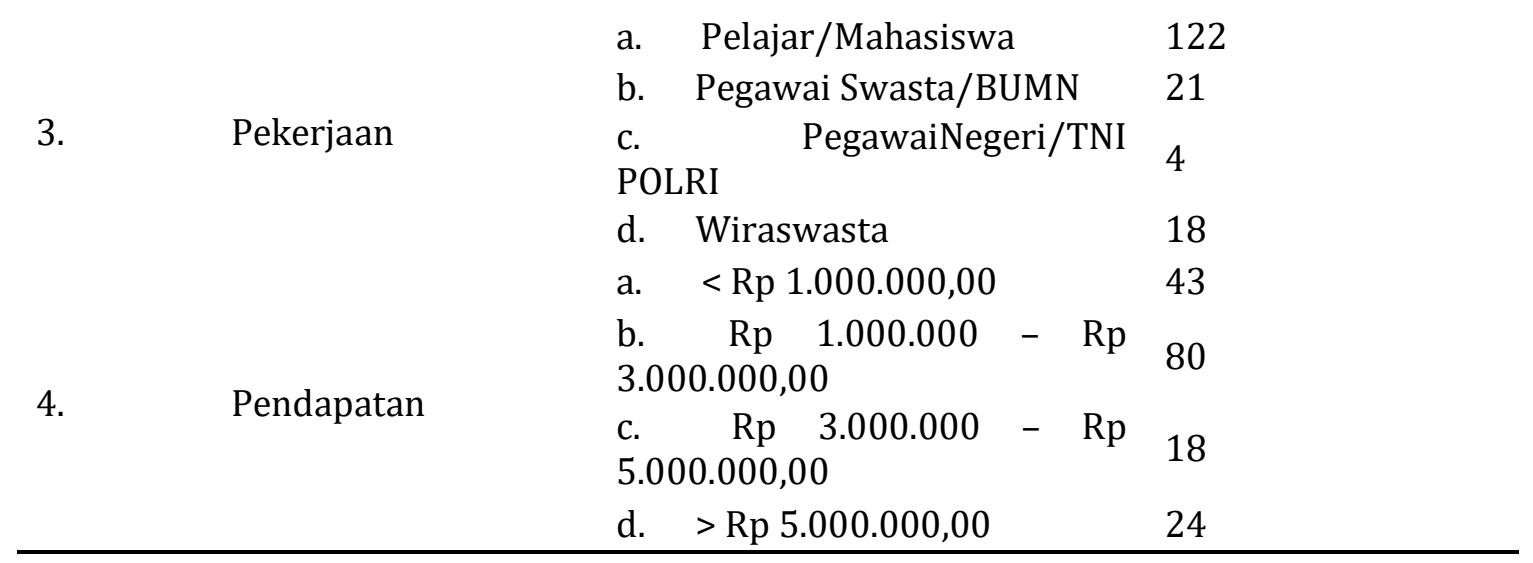

Gambar 2. Full Model Structural Equation Model

Tabel 3. Ringkasan Hasil Uji Kesesuaian Model (Goodness of Fit)

\begin{tabular}{llll}
\hline $\begin{array}{l}\text { Goodness of fit } \\
\text { Index }\end{array}$ & $\begin{array}{l}\text { Hasil } \\
\text { Analisis }\end{array}$ & Cut of Value & $\begin{array}{l}\text { Evaluasi } \\
\text { Model }\end{array}$ \\
\hline X$^{2}$-Chi-Square & 605,275 & $<210,176$ & Marginal \\
Probability & 0 & $>0,05$ & Marginal \\
CMIN/DF & 1,366 & $<2,00$ & Baik \\
GFI & 0,824 & $>0,90$ & Marginal \\
AGFI & 0,79 & $>0,90$ & Marginal \\
TLI & 0,952 & $>0,95$ & Baik \\
CFI & 0,957 & $>0,95$ & Baik \\
RMSEA & 0,047 & $<0,08$ & Baik \\
\hline
\end{tabular}

Dari hasil pengujian kelayakan model Structural Equation Model (SEM) diatas yang telah ditampilkan dapat dilihat nilai dari chi-square sebesar 605, 275 dengan tingkat signifikansi sebesar < 210, 176 menunjukkan bahwa model yang digunakan dapat diterima marjinal. Namun model yang digunakan dapat diterima dengan baik didasarkan pada kriteria dimana nilai signifikansi yang lebih besar dari 0,05 mengindikasikan model tersebut merupakan model persamaan struktural yang baik. Selain itu, indeks pengukuran CMIN/DF, TLI, CFI dan RMSEA juga berada dalam rentang nilai yang diharapkan, meskipun nilai GFI dan AGFI diterima secara marginal karena disebabkan variasi data. Dengan demikian dapat disimpulkan bahwa uji kelayakan model Structural Equation Model (SEM) sudah memenuhi syarat penerimaan. Hal tersebut mengartikan bahwa konstruk-konstruk yang digunakan untuk membentuk sebuah model penelitian telah memenuhi kriteria kelayakan sebuah model, sehingga model yang digunakan dapat diterima dan dapat dianalisis.

\section{PENGUJIAN HIPOTESIS}

Pada penelitian ini terdapat 5 hipotesis yang diajukan. Berikut adalah tabel pengujian hipotesis dalam analisis SEM:

Tabel 4. Standarized Regression Weight untuk Pengujian Hipotesis

\begin{tabular}{lclcc}
\hline Hubungan Kausal & & & C.R. & $t_{\text {tabel }}$ \\
\hline Kepuasan_Konsumen & $<---$ & Citra_Merek & 3,849 & 1,660 \\
Kepuasan_Konsumen & $<---$ & Keragaman_Menu & 2,855 & 1,660
\end{tabular}


(Studi Pada Konsumen Society Coffee House Purwokerto)

\begin{tabular}{lclcc}
\hline Hubungan Kausal & & & C.R. & $t_{\text {tabel }}$ \\
\hline Kepuasan_Konsumen & $<---$ & Suasana_Toko & 3,342 & 1,660 \\
Kepuasan_Konsumen & $<---$ & Kualitas_Produk & 4,123 & 1,660 \\
Niat_Beli_Ulang & $<---$ & Kepuasan_Konsumen & 12,314 & 1,660 \\
\hline
\end{tabular}

Hasil pengujian Structural Equation Model (SEM) didapati bahwa semua variabel memiliki koefisien yang positif. Hal ini sesuai dengan yang dihipotesiskan. Penjelasan untuk pengujian hipotesis di atas adalah sebagai berikut:

Nilai critical ratio (CR) untuk pengaruh variabel citra merek terhadap kepuasan konsumen sebesar 3,849 lebih besar dari nilai tabel. Dengan demikian, maka hipotesis pertama (H1) yang menyatakan bahwa citra merek berpengaruh positif terhadap kepuasan konsumen, diterima. Nilai critical ratio (CR) untuk pengaruh variabel keragaman menu terhadap kepuasan konsumen sebesar 2,855 lebih besar dari nilai $t_{\text {tabel. }}$ hipotesis kedua (H2) yang menyatakan bahwa keragaman menu berpengaruh positif terhadap kepuasan konsumen, diterima. Nilai critical ratio (CR) untuk pengaruh variabel suasana toko terhadap niat beli ulang sebesar 3,342 juga lebih besar dari nilai $t_{\text {tabel. }}$. Hipotesis ketiga (H3) yang menyatakan bahwa suasana toko berpengaruh positif terhadap kepuasan konsumen, diterima. Nilai critical ratio (CR) untuk pengaruh variabel kualitas produk terhadap niat beli ulang sebesar 4,123 lebih besar dari nilai $t_{\text {tabel. }}$. Hipotesis keempat $(\mathrm{H} 4)$ yang menyatakan bahwa kualitas produk berpengaruh positif terhadap kepuasan konsumen, diterima. Nilai critical ratio (CR) untuk pengaruh variabel kepuasan konsumen terhadap niat beli ulang sebesar 12,314 juga lebih besar dari nilai tabel. Hipotesis kelima (H5) yang menyatakan bahwa kepuasan konsumen berpengaruh positif terhadap niat beli ulang, diterima.

\section{KESIMPULAN DAN IMPLIKASI}

\section{Kesimpulan}

Kesimpulan yang didapat dari penelitian ini adalah bahwa citra merek berpengaruh positif terhadap kepuasan konsumen Society Coffee House di Purwokerto, keragaman menu berpengaruh positif terhadap kepuasan konsumen Society Coffee House di Purwokerto, suasana toko berpengaruh positif terhadap kepuasan konsumen Society Coffee House di Purwokerto, kualitas produk berpengaruh positif terhadap kepuasan konsumen Society Coffee House di Purwokerto dan kepuasan konsumen berpengaruh positif terhadap niat beli ulang di Society Coffee House Purwokerto.

\section{Implikasi}

Berdasarkan penelitian ini hasil pengukuran goodness of fit SEM yaitu Chi-Square dan probability, serta Goodness of-Fit Index (GFI) dan Adjusted Goodness of Fit Index (AGFI) masih dalam kategori marginal. Sehingga implikasi untuk penelitian selanjutnya disarankan dapat menggunakan alat analisis lainnya dan dilakukan pada subjek lain atau pada industri lainnya, selain hospitality industry.

\section{DAFTAR PUSTAKA}

Ahmed, E Baiomy \& Eleri Jones and Mark M H Goode. 2017. The Influence of Menu Design, Menu Item Descriptions and Menu Variety on Customer Satisfaction. A case study of Egypt. Tourism and Hospitality Research 0(0) 1-12 
Menu Item Descriptions and Menu Variety on Customer Satisfaction. A Case Study of Egypt. International Journal of Hospitality Management 57, 71-83

Ali, Faizan Rosmini Omar \& Muslim Amin. 2013. An Examination of the Relationships between Physical Environment, Perceived Value, Image and Behavioural Intentions: A SEM approach towards Malaysian resort hotels.

Assael, Henry. 2001. Consumer Behavior 6th Edition. New York: ThomsonLearning.

Azzahra, F. 2011. Pengaruh Penggunaan Electronic Book Terdatabase Ber-Hypermedia Offline Terhadap Penguasaan Konsep Siswa SMA pada Materi Sistem Indera. Skripsi pada FPMIPA UPI Bandung

Bitner, M. J. (1992). Servicescapes: The Impact Of Physical Surroundings On Customers And Employees. Journal of Marketing, 56(2), 57-71.

Bitner, M. J. dan Zeithaml, V. A., 2003, Service Marketing (3rd ed.), Tata McGraw Hill, New Delhi.

Brady, M. K., \& Cronin, J. J. (2001). Some New Thoughts On Conceptualizing Perceived Service Quality: A Hierarchical Approach. Journal of Marketing, 65(3), 34-49. doi:10.1509/ jmkg.65.3.34.18334

Chang K (2012) How Reputation Creates Loyalty In The Restaurant Sector. International Journal of Contemporary Hospitality Management 25(4): 536-557

Chapagain, A.K. and A.Y. Hoekstra. (2007). The Water Footprint of Coffee and Tea Consumption in The Netherlands. Ecological Economic 64 ( 2007 ) 109-118

Chen, C. M., Lee, H. T., Chen, S. H., \& Huang, T. H. (2011). Tourist Behavioural Intentions In Relation To Service Quality And Customer Satisfaction In Kinmen National Park, Taiwan. International Journal of Tourism Research, 13(5), 416-432. doi:10.1002/jtr.810

Chi, C. G. Q., \& Qu, H. (2008). Examining The Structural Relationships Of Destination Image, Tourist Satisfaction And Destination Loyalty: An Integrated Approach. Tourism Management, 29(4), 624-636. doi:10.1016/j.tourman.2007.06.007

Copper, R. D., Emory, W. 1996. Metode Penelitian Bisnis jilid 1. Jakarta : Erlangga.

Dodds, W. B., Monroe, K. B., \& Grewal, D. (1991). Effects Of Price, Brand, And Store Information On Buyers Product Evaluations. Journal of Marketing Research, 28(3), 307-319.

Dr. Fariddedin, Allameh Haery \& Mozhdeh Badiezadeh. 2014. Studying The Effect Of Food Quality Dimensions (Physical Environment, Food And Services) On Mental Image Of The Restaurant And Customers' Satisfaction And Intentions Based On Kisang's Model. International Journal of Academic Research in Business and Social Sciences Vol. 4, No. 7

Engels. James F., Roger D. Blackwell, Paul .W Miniad.1995. Perilaku Konsumen, edisi ke 6 jilid kedua . Jakarta : Binarupa Aksara

Faizan, Ali \& Muslim Amin. 2014. The Influence Of Physical Environment On Emotions, Customer Satisfaction And Behavioural Intentions In Chinese Resort Hotel Industry. J. Global Business Advancement, Vol. 7, No. 3

Fornell, C. (1992) A National Customer Satisfaction Barometer: The Swedish Experience. Journal of Marketing, Vol. 56. 
Garvin, David. 1994. Kualitas Produk: Alat Strategi yang Penting, Jakarta: Free Press.

Ghozali, Imam. 2008. Aplikasi Analisis Multivariate dengan Program SPSS. Semarang: Badan Penerbit Universitas Diponegoro.

H. and Kim, W. (2009). Outcomes Of Relational Benefits: Restaurant Customers Perspective. Journal of Travel \& Tourism Marketing, Vol. 26, No. 8, pp.820-835.

Ha, J., \& Jang, S. (2010a). Perceived Values, Satisfaction, And Behavioral Intentions: The Role Of Familiarity In Korean Restaurants. International Journal of Hospitality Management, 29(1), 2-13.

Hair et al., (1998), Multivariate Data Analysis, Fifth Edition, Prentice Hall, Upper Saddle River : New Jersy.

Hamed, Moslehi \& Farideddin Allameh Haeri. 2016. Effect Of Promotions On Perceived Quality And Repurchase Intention. International Journal of Scientific Management and Development, Vol.4, No.12 pp:457-461

Hellier, et al. (2003). Repurchase Intention: A General Structural Equation Model. Journal of marketing, 37, 1762-1800

Hoeffler, S. dan Keller, K.K. (2003), "The marketing advantages of strong brands", Brand Management, Vol. 10 No. 6, pp. 421-45.

Hung-Che Wu, Chi-Han Ai, Lei-Jiao Yang \& Tao Li. 2015. A Study Of Revisit Intentions, Customer Satisfaction, Corporate Image, Emotions And Service Quality In The Hot Spring Industry. Journal of China Tourism Research, 11: 371-401.

Ivyanno U. Canny. 2014. Measuring The Mediating Role Of Dining Experience Attributes On Customer Satisfaction And Its Impact On Behavioral Intentions Of Casual Dining Restaurant In Jakarta. International Journal of Innovation, Management and Technology, Vol. 5, No. 1

Jani, D. and Han, H. (2011). Investigating The Key Factors Affecting Behavioral Intentions: Evidence From A Full-Service Restaurant Setting. International Journal of Contemporary Hospitality Management, Vol. 23, No. 7, pp.1000-1018.

Kandampully, J., \& Suhartanto, D. (2000). Customer Loyalty In The Hotel Industry: The Role Of Customer Satisfaction And Image. International Journal of Contemporary Hospitality Management, 12(6), 346-351. doi:10.1108/09596110010342559

Kevin Lane Keller., 2003, Strategic Brand Manajemen, Second Edition, Prentice Hall

Khuong, Mai Ngoc \&Tran Tran Uyen. 2015. Factors Affecting Guest Perceived Service Quality, Product Quality, And Satisfaction-A Study Of Luxury Restaurants In Ho Chi Minh City. Journal of Advanced Management Science Vol. 3, No. 4

Kisang Ryu, Hye-Rin Lee, and Woo Gon Kim. 2016. The Influence Of The Quality Of The Physical Environment, Food, And Service On Restaurant Image, Customer Perceived Value, Customer Satisfaction, And Behavioral Intentions. International Journal of Contemporary Hospitality Management Vol. 24 No. 2

Ko, Y. J., \& Pastore, D. L. (2005). A Hierarchical Model Of Service Quality For The Recreational Sport Industry. Sport Marketing Quarterly, 14(2), 84-97. Kotler, Amstrong. 2001. Prinsip-Prinsip Pemasaran, Edisi keduabelas, Jilid 1. Jakarta: Erlangga. 
Kotler, 2005. Manajemen Pemasaran, Jilid I dan II. Jakarta : PT. Indeks.

Kotler dan Keller. 2009. Manajemen Pemasaran. Jilid 1. Edisi ke 13. Jakarta : Erlangga

Kuan-Yu Chen. 2014. Assessing The Effect Of Restaurant-Related Attributes On Customer Behavioral Intentions.

Kurniawati, Dewi, dkk. 2014, "Pengaruh Citra Merek dan Kualitas Produk Terhadap Kepuasan dan Loyalitas Pelanggan", Jurnal Administrasi Bisnis (JAB), Vol. 14, No. 2.

Kuo-Chien Chang. 2015. Effect Of Servicescape On Customer Behavioral Intentions : Moderating Roles Of Service Climate And Employee Engagement.

Ladhari, R. (2009). Service Quality, Emotional Satisfaction, And Behavioral Intentions: A Study In The Managing Service Quality, Vol. 19, No. 3, pp.308-331. Lovelock, Christoper dan Jochen Wirtz. 2011. Service Marketing. New Jersey USA: Pearson.

Lovelock, Christopher, Jochen Wirtz, \& Jacky Mussry. 2011. Pemasaran Jasa. edisi 7. Erlangga: Jakarta

Lupiyoadi , Rambat. 2001. Manajemen Pemasaran Jasa. Jakarta : PT. Salemba Empat.

Naehyun (Paul) Jin a, Sangmook Lee a \& Lynn Huffman, 2013. Impact of Restaurant Experience on Brand Image and Customer Loyalty: Moderating Role of Dining Motivation. United State : Journal of Travel \& Tourism Marketing, 29:532-551

Nguyen, N., \& Leblanc, G. (2002). Contact Personnel, Physical Environment And The Perceived Corporate Image Of Intangible Services By New Clients. International Journal of Service Industry Management, 13(3), 242-262.

Park, C.W., Jaworski, B.J., \& MacInnis, D.J. (1986). Strategic brand conceptimage management. Journal of Marketing, 50(4), 135-145.

Ryu, K., Lee, H. and Kim, W. (2012). The Influence Of The Quality Of The Physical Environment, Food, And Service On Restaurant Image, Customer Perceived Value, Customer Satisfaction, And Behavioral Intentions. International Journal of Contemporary Hospitality Management, Vol. 24, No. 2, pp.200-223.

Samaan Al-Msallam, 2015. Customer Satisfaction And Brand Loyalty In The Hotel Industry. European Scientific Journal, Vol.1

Sarwono, Jonathan. (2006). Metode Penelitian Kuantitatif \& Kualitatif. Yogykarta: Graha Ilmu.

Scanlon, N. (1999). Marketing by Menu, 3rd ed. New Jersey: John Wiley.

Schiffman, L. G., \& Kanuk, L. L. (2000). Consumer Behavior. Upper Saddle River, NJ: Prentice Hall.

Shoch P and Stefanelli J. (1992). Hotel Catering: A Handbook for Sales and Operations. New York: John Wiley \& Sons

Shoemaker S, Dawson M and Johnson W (2005) How to increase menu prices without altering your customers. International Journal of Contemporary Hospitality Management 17(7): 553-568.

Shwu-Ing Wu \& Wen-Hsuan Wang, 2014. Impact of CSR Perception on Brand Image, Band Attitude and Buying Willingness : A Study of a Global Cafe. European Journal of Business and Management Vol.6, No.36 
Menilai Pengaruh Citra Merek, Keragaman Menu, Suasana Toko dan Kualitas Produk Terhadap Kepuasan Konsumen dan Niat Beli Ulang

(Studi Pada Konsumen Society Coffee House Purwokerto)

Sparks, Richard E. And Richard D. Legault, 2005. A Definition of Quality for Total Customer Satisfaction : The Bridge between Manufacturer and Customer. Sam Advanced Management Journal, Winter, p16-27

Sugiyono. 2001. Perilaku Pembelian Konsumen dan Komunikasi Pemasaran. Rosda: Bandung 2009. Metode Penelitian Kuantitatif, Kualitatif dan R\&D. Bandung : Alfabeta.

2010. Metode Penelitian Pendidikan Pendekatan Kuantitatif, Kualitatif, Dan R\&D. Bandung: Alfabeta

2013. Metode Penelitian Pendidikan Pendekatan Kuantitatif, Kualitatif, dan R\&D. Bandung: Alfabeta.

Suliyanto. 2006. Metode Riset Bisnis. Yogyakarta: Andi

2011. Ekonometrika Terapan: Teori dan Aplikasi dengan SPSS. Yogyakarta: ANDI.

Suwartono.(2014). Dasar-dasar Metodologi Penelitian. Yogyakarta: Andy Offset. Tjiptono, Fandy, 2004. Strategi Pemasaran, Edisi 2. Yogyakarta : Penerbit Andi.

Tjiptono, Fandy. (2011). Strategi Pemasaran. Edisi 3. Yogyakarta : ANDI.

Verhoef, P. C., Lemon, K. N., Parasuraman, A., Roggeveen, A., Tsiros, M., \& Schlesinger, L. A. (2009). Customer experience creation: Determinants, dynamics and management strategies. Journal of Retailing, 85(1), 31-41.

Wu, H. C. (2014). The Effects Of Customer Satisfaction, Perceived Value, Corporate Image And Service Quality On Behavioral Intentions In Gaming Establishments. Asia Pacific Journal of Marketing and Logistics, 26(4), 540-565. doi:10.1108/APJML-03-20140049

Zainal Mustafa, 2009. Mengurai Variabel hingga Instrumentasi,Yogyakarta : Graha Ilmu.

Zeithaml dan Bitner, 2003. Service Marketing Integrating Customer Focus Across the Firm, 3rd edition. Boston. Mc GrowHill/Irwin

Sumber Internet

http://satelitpost.com/regional/pertumbuhan-ekonomi-banyumas-lampaui-provinsi

http://www.beritasatu.com/nasional/301078-gubernur-jateng-purwokerto-pusatpertumbuhan-ekonomi-baru.html

http://jateng.bps.go.id/index.php/linkTabelStatis/1340

http://agro.kemenperin.go.id/3362-Gaya-Hidup-Remaja-Dongkrak-Konsumsi-Kopi

http://www.skyscrapercity.com/showthread.php?t=1982445 